\title{
Sentential negation in South African Sign Language: A case study
}

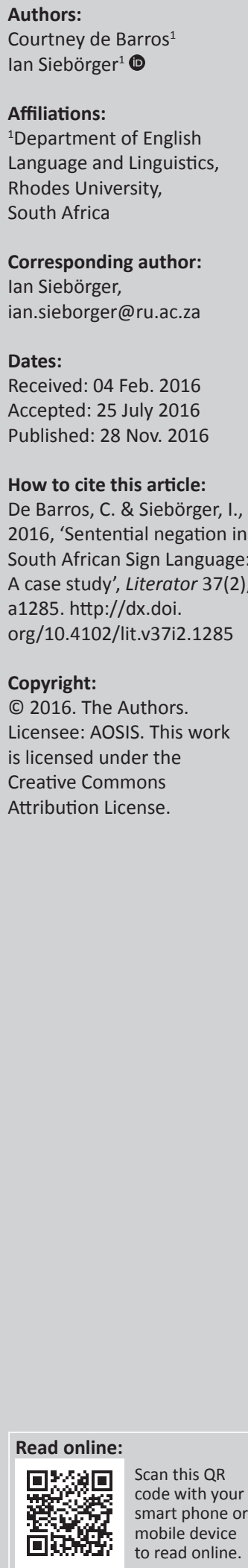

As with other sign languages, South African Sign Language (SASL) expresses negation using both manual and non-manual features. In this case study, naturalistic data provided by two native signers of SASL are analysed to show the syntactic relationship between these two sets of features. Using a Principles and Parameters approach and Government and Binding Theory, we investigate the syntactic scope of negation in our SASL data. We observe that side-to-side headshake, as a non-manual feature, appears to be the chief clausal negator in SASL, with a clause-final manual negative particle, NOT, playing a secondary role. We describe the negative headshake as a featural affix which is base-generated in the head of NegP and triggers V-toNeg raising. The negative particle NOT appears to be base-generated in the Specifier of NegP. Suggestions for further syntactic research on SASL are provided.

Sinsontkenning in Suid-Afrikaanse Gebaretaal: 'n Gevallestudie. Soos ander gebaretale, maak Suid-Afrikaanse Gebaretaal (SAGT) gebruik van beide die hande en ander dele van die liggaam om ontkenning uit te druk. In hierdie gevallestudie word naturalistiese data voorsien deur twee moedertaal-gebruikers van SAGT geanaliseer om die sintaktiese verhouding tussen hierdie twee wyses van ontkenning te toon. Ons gebruik' $n$ Principles and Parameters-benadering en Government and Binding Theory om die sintaksiese omvang van ontkenning in ons SAGTdata te ondersoek. Uit ons waarneming blyk dat'n skud van die kop van kant tot kant skynbaar die vernaamste merker van ontkenning in 'n SAGT-sin uitmaak. 'n Negatiewe deeltjie wat met die hande gemaak word aan die einde van die sin, NIE, speel 'n sekondêre rol. Ons beskryf die negatiewe kopskud as 'n kenmerk-draende voegsel wat onderliggend in die hoof van NegP gegenereer word en V-na-Neg-verhoging inisieer. Die negatiewe deeltiie NIE lyk asof dit onderliggend in die Spesifiseerder van NegP gegenereer word. Voorstelle vir verdere sinktaktiese ondersoek van SAGT word ten slotte gemaak.

\section{Introduction}

While spoken languages are 'produced by the vocal tract and perceived by the auditory channel' (Perniss et al. 2007:1), sign languages by contrast 'are produced by the hands, but also by other non-manual articulators like the head, face and body and are perceived visually' (Perniss et al. 2007:2). This means that natural human languages exist in two different modalities, and so any attempt to describe the universal elements of language structure is incomplete without the inclusion of research on sign languages.

However, research into sign languages is a relatively new field that has only developed over the past four decades. Over the past 20 years the majority of research published on South African Sign Language (SASL) has been related to language policy (see e.g. Aarons \& Akach 1998; Penn \& Reagan 1990; Reagan 2008; Reagan, Penn \& Ogilvy 2006), with almost no attention paid to the formal features of the language. Syntactic research on SASL (Aarons \& Morgan 2003; Vermeerbergen et al. 2007) is extremely rare, and to date we are not aware of any published academic research on negation in SASL. This study aimed to help fill this gap in the literature.

Sign languages produce features like negation in a different way to spoken language because of the corporal-visual channel of communication that they employ. Negation in sign language makes use of both manual and non-manual features to convey meaning. As discussed in the 'Sentential negation' section, the relationship between negative non-manual features and negative manual signs varies between sign languages. Thus, research on negation provides important insights into the effects of the corporal-visual modality on language, as well as morphosyntactic variation between sign languages.

This article reports on an exploratory case study showing how the syntax of negation in SASL can be described using a Principles and Parameters approach as well as Government and Binding 
Theory (Chomsky 1982). This case study is based on a limited dataset, one naturalistic conversation between two signers who are friends, but it provides a basis for further research into the syntax of negation in SASL. Our analysis answers the following questions:

- What is the syntactic structure of sentential negation in SASL?

- How do manual signs and non-manual features denoting sentential negation in SASL interact with each other?

- What relationship, if any, exists between the phonological scope of the non-manual features of negation and the syntactic scope of sentential negation in SASL?

- What is the relationship between sentential negation in SASL and this type of negation in other sign languages?

\section{Negation across sign and spoken languages \\ Introduction}

According to Bussman (1996), 'the linguistic description of negation has proven to be a difficult problem in all grammatical models owing to the complex interrelationship of syntactic, prosodic, semantic, and pragmatic aspects' (p. 323). In sign languages this includes the challenge of capturing the interaction of manual and non-manual features of negation.

\section{Components of sign language negation}

\section{Manual negation}

Manual negation in sign language uses a variety of special signs with different syntactic properties. These include negative particles like NO and NOT and negation signs such as NOBODY or NOTHING. A less regular morphological form of negation has also been found. Here a negative affix is sequentially added to a sign that undergoes some kind of phonological change in order to incorporate it (Antzakas 2006:38). These constructions are referred to as signs of negative incorporation.

Negation signs and negative particles: Most sign languages appear to make use of uninflected negative particles (Zeshan 2004). The use of negative particles appears to vary quite widely in sign languages. The negative particle NO appears to be the most common and was found in all the 38 sign languages analysed in Zeshan's (2004) typological study. Other negative particles have been found to be more idiosyncratic in individual sign languages. Negation signs, which not only reverse the polarity of the clause but also add more semantic specification to the negation, also differ cross-linguistically. The most common ones found in Zeshan's study are negative completives such as NOT-YET, emphatic negatives like NOT-AT-ALL, REALLY-NOT and ABSOLUTELY-NOT and negative interjections such as NO, NOT-AT-ALL and NOT-ME, which were used as one-word answers to questions.

Irregular negation or signs of negative incorporation: Sign languages also use bound morphemes to convey negation; however, this strategy is far less common. The use of morphology is limited in that 'they (negative morphemes) never cover the whole range of predicates, but always apply to a limited number of signs' (Zeshan 2004:30). For example, in American Sign Language (ASL), Woodward (1974:22) describes 'several verbs that may be negated by a bound outward twisting movement of the moving hands from the place where the sign is made'. Sutton-Spence and Woll have found in British Sign Language (BSL) that bound negative morphemes often occur with 'verbs of experience or sensation' (1999:77), e.g. HAVE-NOT, KNOW-NOT, LIKENOT. A number of sign languages have similar constructions to this and in Zeshan's study the most common group of signs that incorporated this irregular negation were negative existentials such as NOT-EXIST, THERE-IS/ARE-NOT and negative modals such as CANNOT, NEED-NOT, WILL-NOT or SHOULD-NOT.

\section{Non-manual negation}

Negative non-manual features are articulated using headmovements, ${ }^{1}$ facial expressions and movements of the body (Liddell 2003). Sandler and Lillo-Martin (2006) claim that for all sign languages non-manual features play a critical role in negation. Several similar forms are found across sign languages, although their exact uses can vary.

Negation head-movement: The most common strategy for negating sentences in sign language is through the use of a 'head-movement' which has been classified as a non-manual feature. There are three main forms of this 'head-movement' that have been described: a headshake, head turn and head tilt (Zeshan 2004). The headshake appears to be the most common form and is a repeated side-to-side movement of the head rotating round the neck as an axis. The second kind of head-movement, the head turn, has been described by Sutton-Spence and Woll (1999) in BSL. Here, the head makes a single movement where it is turned to the side and held there. Zeshan (2004) comments that the difference between the head turn and the headshake is unclear, and so the head turn has just been assumed to be a reduced form of the headshake. The third type of head-movement appears to be very rare and is described as a single movement of the head tilting backwards. This head-movement is frequent in Greek Sign Language and is similar to the negative headshake (Antzakas 2006). To prevent confusion with the syntactic term 'head movement', in the sections that follow we use 'headshake' to refer to all types of head-movements.

The nature of the head-movements means that they are able to occur simultaneously with other manual signs. This feature enables sign languages to produce propositions at a similar rate to that of spoken language (Sandler \& LilloMartin 2006). These non-manuals can occur over a single sign, a part of a clause or a whole clause. This is what is

1.Here we use 'head-movement' to refer to the physical action of moving the head, whereas 'head movement' refers to a syntactic operation in which the heads of phrases are moved. 
referred to as the phonological scope of non-manual features. Each sign language specifies under what conditions a nonmanual can occur for a sentence to be grammatical. There are four possibilities for the scope which negation headmovements can cover. They can either occur over the manual negation sign, over both a negation sign and the verb, over the entire clause that includes a manual negator or over the entire clause not including a manual negator (Zeshan 2004).

Negation facial expressions: Facial expressions are the second kind of negative non-manual feature found in sign languages. Negative facial expressions are generally characterised by a frown with the eyebrows lowered as well as a tensing of the nose and upper lip (Liddell 2003). However, there appear to be subtle cross-linguistic differences in the facial expressions used. The major debate around facial features in sign languages is whether they have the same function as headshake or are simply an affective feature. ${ }^{2}$

Negative headshakes are usually considered to be grammatical non-manual features because they appear in negative sentences, their appearance is regular and their scope is related to the manual negation signs (Antzakas 2006). Furthermore, negative headshakes can negate a sentence where there is a manual negative component absent (Zeshan 2004). By contrast, the grammatical status of facial features in negation is less salient and they typically cannot negate a clause on their own. For this reason, we do not concentrate on negation facial expressions in our study, but rather focus on the scope of the headshake.

\section{The syntactic scope of negation}

Scope, in the syntactic sense, is referred to as 'the range that is governed by an operator', and in terms of negation this is seen as the parts of the sentence that are affected by the negation (Antzakas 2006:34).

Klima (1964) was one of the earliest theorists to provide a detailed analysis of sign language negation using generative grammar. He posited that negation can take place in one of two ways: either through sentential/clausal negation or constituent/local negation. Syntactic scope is what differentiates these two forms of negation. Sentential negation occurs where the verb of the clause and consequently the whole clause is negated' (Antzakas 2006:35), as in the sentence, 'Peter did not go to school today'. Meanwhile, constituent negation is 'where a part of the clause other than the verb is negated' (Antzakas 2006:35), as in the sentence 'He went to the beach, not to school'.

The syntactic scope of negation differs from the phonological scope of the headshake used to denote negation in sign languages, but these two types of scope have a very close relationship and are often co-extensive, as is shown in this section and 'The form and structure of negation in SASL' section.

\section{Sentential negation}

Pollock (1989) argued that negation was part of the same system as agreement and tense. These were all considered to be functional elements that made up what used to be called 'inflection'. He argued for the existence of a functional category called the negation phrase (NegP), with a head, labelled $\mathrm{Neg}^{\circ}$, which has its own set of negation (NEG) features (Antzakas 2006). Haegeman later refined this and posited that 'there exists a tight syntactic connection between the negative head $\mathrm{Neg}^{\circ}$ on the one hand and negative phrases on the other' (1995:138). Negative adverbials occur in the specifier position of NegP and include words like 'never' in English and 'personne' ['nobody'], 'jamais' ['never'] and 'pas', the negative concord marker in French. This relationship between the negative head and the negative adverbial in the specifier position in the Principles and Parameters Model is expressed as a 'relation between a head and its local specifier' (Haegeman 1995:249). From this, the NEG criterion was fashioned, which applies to sentential negation and not constituent negation. This criterion stipulates that:

- A NEG-operator must be in the Spec-head configuration with an $X^{\circ}[\mathrm{NEG}]$

- An $X^{\circ}[\mathrm{Neg}]$ must be in a Spec-head configuration with a Neg-operator.

Where the following definitions obtain:

- NEG-operator: a negative phrase in a scope position.

- Scope position: left-peripheral $\mathrm{A}^{\prime}$-position [Spec, XP] or [YP, XP] (Haegeman 1995:106).

According to the NEG-criterion, 'a Spec-Head [specifierhead] relation is responsible for sentential negation' (Antzakas 2006:35).

To summarise, in spoken language sentential negative elements are the head of their own functional category, usually known as NegP (Sandler \& Lillo-Martin 2006). This same NegP is used to explain sentential negation in sign languages; however, not all sign languages employ sentential negation in the same way. This is because the relationship between the manual negation sign and negative headshakes varies across sign languages. ASL, German Sign Language (DGS) and Catalan Sign Language (LSC) are explored in the following section to indicate how the manual negation sign and negative headshake interact. The manual negation sign is optional in most sign languages, and it is possible to negate using non-manual negation only. However, depending on the role that manual negation signs and headshakes play in sentential negation, different elements will fill the specifier and head position of the NegP. We explore these different sign languages to show how manual and non-manual negation elements may have different morphosyntactic properties and thus occupy different positions within NegP.

\section{Placement of sentential negation and word order in sign language}

In sign languages the placement of the NegP appears to vary, and so Sandler and Lillo-Martin (2006) postulate two general 
forms. The first is a preverbal placement and the second is a postverbal placement. They also suggest that the postverbal position of a negative item often coincides with the final position of the sentence. What distinguishes the placement of preverbal or postverbal negation appears to be related to the word order of the particular sign language.

Pfau and Quer (2003) claim that DGS and LSC have an SOV word order. These sign languages then employ a postverbal placement of the manual negator, usually occuring in clausefinal position. Conversely, according to Neidle et al. (2000), ASL has an SVO word order and thus employs preverbal negation when the negative particle NOT is used.

The hierarchical position of the negative element is thus brought into question. How is the negative element placed to reflect the alternate structuring of ASL as an SVO sign language and DGS and LSC as SOV sign languages? The two different structures require very different syntactic arrangements of the negative element. According to Cinque (1999) and Zanuttini (1997), 'two options are available: TP (tense phrase) selecting NegP or NegP selecting $\mathrm{TP}^{\prime}$ (cited in Sandler \& Lillo-Martin 2006:364).

In ASL, in order for a negative sentence to be grammatical, the headshake can either occur over just the manual negation sign (see Eqn 1a) or over the whole clause, excluding the TP, and manual negation sign (see Eqn 1b). A manual sign alone is enough to negate the sentence in ASL, but only in specific discourse contexts (Liddell 2003). Negating a sentence with headshake alone is also grammatical in ASL (see Eqn 1c). Furthermore, Liddell (2003) comments that when the manual sign is absent the non-manual feature spreads over the VP (verb phrase).

\section{ASL. Adapted from Neidle et al. (2000:44-45):}

a) JOHN $\frac{\text { neg }}{\text { NOT }}$ BUY HOUSE John is not buying a house

b)

JOHN NOT BUY HOUSE

John is not buying a house

c) JOHN $\frac{\text { neg }}{n y y \text { HOUSE }}$

John is not buying a house

[Eqn 1]

Neidle et al. (2000) posit that the manual negation sign assumes the head of the NegP and the negative headshake is realised as a [+neg] feature and thus occurs in the head of NegP (Sandler \& Lillo-Martin 2006). The negative nonmanual marker spreads over the c-command ${ }^{3}$ domain of NegP excluding the subject. In terms of phrase structure for ASL the NegP occurs below the TP, above AspP and VP.

Pfau and Quer (2003) depict their analyses of the syntax of the negative particle in ASL as in (Eqn 2). According to Pfau and Quer (2003) the verb does not raise in ASL. When the manual negative particle NOT is present

the headshake can associate with NOT and therefore headshake on NOT only is grammatical ... however when NOT is not present, [+neg] has no manual material to be articulated with and is therefore forced to spread over its entire c-command domain. (Pfau \& Quer 2003:77)

Movement of the negative particle in ASL. Adapted from Pfau and Quer (2003:77):

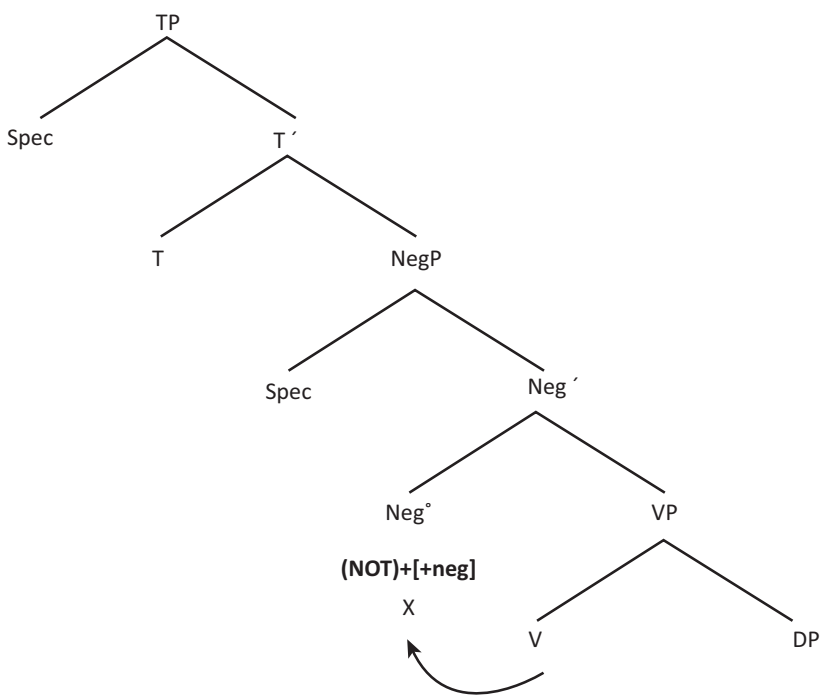

[Eqn 2]

Pfau and Quer (2003) present some aspects of the syntax of sentential negation for both LSC and DGS. The following description of these aspects draws extensively on their work. In both these sign languages the underlying word order is SOV, and headshake negation is obligatory. A crucial difference between ASL on the one hand and LSC and DGS on the other hand concerns the status of the [+neg] feature. In ASL the [+neg] feature is syntactic, while in LSC and DGS it is morphological and is considered to be a featural affix. Akinlabi (1996) describes featural affixes as phonological features that function as grammatical morphemes. The [+neg] feature is considered a featural affix in LSC and DGS because it can have different morphosyntactic properties depending on what is grammatical in the sign language. In ASL the operations of the [+neg] feature are governed by syntactic rules and that is why c-command is used to explain the syntactic scope of negation in ASL. However, as we will see, for LSC and DGS morphological rules govern the operations of the [+neg] feature and movement is triggered by the Stray Affix Filter in order to explain the syntactic scope of negation in these sign languages.

The Stray Affix Filter stipulates that affixes must have phonologically overt hosts (Lasnik 1981, 1995). This basically means that a bound morpheme cannot be produced in isolation. In LSC and DGS the headshake is considered to be an affix/bound morpheme. The violation of the Stray Affix Filter is what causes the verb to move in order for the affix, in this case the headshake, to have manual material to co-occur with. 
In LSC it is grammatical for the headshake only to occur over the verb (see Eqn 3a, in which there is no manual negator, but only negative headshake) or over the manual negator, NO (see Eqn 3b). If a non-manual sign is not present then the spreading of the negation does not happen in the same way as ASL because [+neg] is a featural affix. This means that whenever $\mathrm{NO}$ is present, $[+\mathrm{neg}]$ will be affixed to $\mathrm{NO}$, and whenever NO is not present, V-to-Neg raising is triggered due to the Stray Affix Filter (Pfau \& Quer 2003). This featural affix's attachment to the verb makes the headshake over only the manual negator grammatical. When there is no manual negator this feature again allows for the headshake only to occur over the verb. This structure is depicted in (Eqn 4). ${ }^{4}$

LSC. Adapted from Pfau and Quer (2003:75):

\begin{tabular}{|c|c|c|c|c|}
\hline \multirow{3}{*}{ a) } & \multirow{3}{*}{$\begin{array}{l}\text { SANTI } \\
\text { Santi }\end{array}$} & \multirow{3}{*}{$\begin{array}{l}\text { CARN } \\
\text { meat }\end{array}$} & \multicolumn{2}{|c|}{ neg } \\
\hline & & & \multirow{2}{*}{$\begin{array}{l}\text { MENJAR } \\
\text { eat }\end{array}$} & \\
\hline & & & & \\
\hline & \multicolumn{3}{|c|}{ Santi does not eat meat } & \\
\hline & & & & neg \\
\hline \multirow{2}{*}{ b) } & SANTI & CARN & MENJAR & $\mathrm{NO}$ \\
\hline & Santi & meat & eat & not \\
\hline
\end{tabular}

Santi does not eat meat

[Eqn 3]

Movement of the negative particle in LSC. Adapted from Pfau and Quer (2003:78):

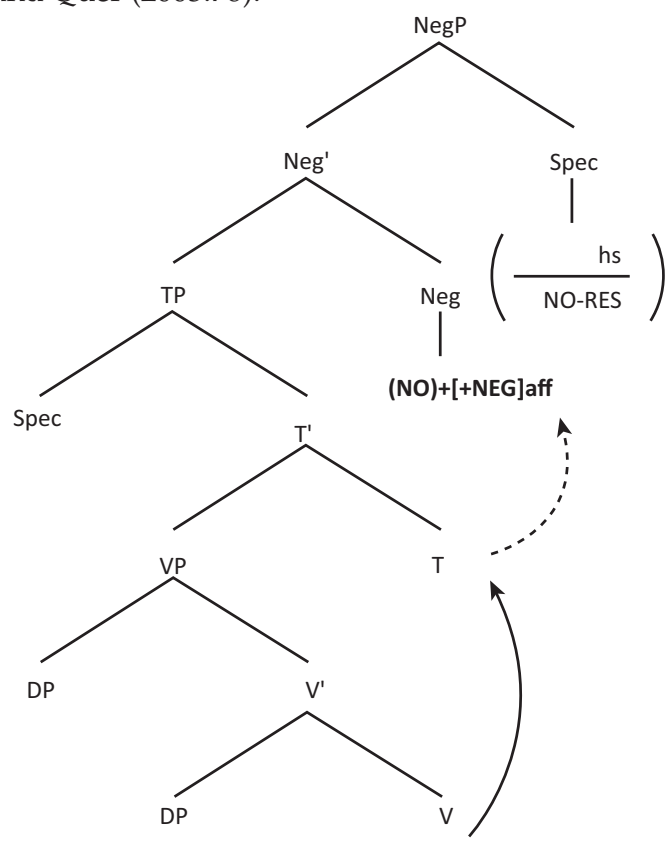

[Eqn 4]

Both LSC and DGS are considered to be 'head-final' languages. In these languages functional categories are headinitial, while lexical categories are proposed to have split heads. Evidence for the use of split-headedness comes from the order of constituents - in particular, the verb follows the complement in a VP. Through the use of the split-headed tree clause-final negation can be explained.

DGS is an SOV language where headshake negation is obligatory and the [+neg] feature is also affixal. For DGS, unlike in LSC, headshake occurring over only a manual negator is insufficient to negate the sentence (see Eqn 5a); it is necessary for the non-manual marking to spread over the verb of the negated verb phrase. When the manual negator is not overt the headshake has to spread over the negated verb or over the negated VP; both constructions are grammatical in this sign language (Pfau \& Quer 2003) (see Eqn 5b). To explain how negation is constructed in DGS, Pfau and Quer (2003) point out that the manual negation sign occupies a specifier position within the negative phrase and is lexically specified for a headshake. The [+neg] affix occupies the Head position in the negative phrase. Because the Specifier position is filled by the manual negation sign, if the verb does not move to $\mathrm{Neg}^{\circ}$ to pick up the [+neg] affix the structure will be ungrammatical; it will have no material to combine with. Moreover, the movement of the verb to Neg position is also obligatory in the absence of the negative particle or any other manual negator (see Eqn 5c) (Pfau \& Quer 2003). A tree diagram for negation in DGS is shown in (Eqn 6).

DGS. Source: Pfau and Quer (2003:79):

a)

$\begin{array}{llll}* \text { MUTTER } & \text { BLUME } & \text { KAUF } & \text { nICHT } \\ \text { Mother flower } & \text { buy } & \text { not }\end{array}$

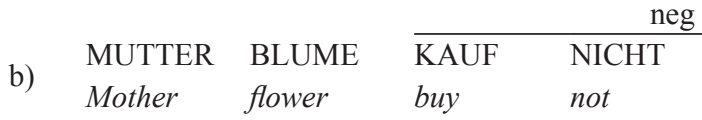

Mother does not buy flowers

MUTTER BLUME KAUF
Mother flower buy
Mother does not buy flowers

[Eqn 5]

Movement of the negative particle in DGS. Adapted from Pfau and Quer (2003:79):

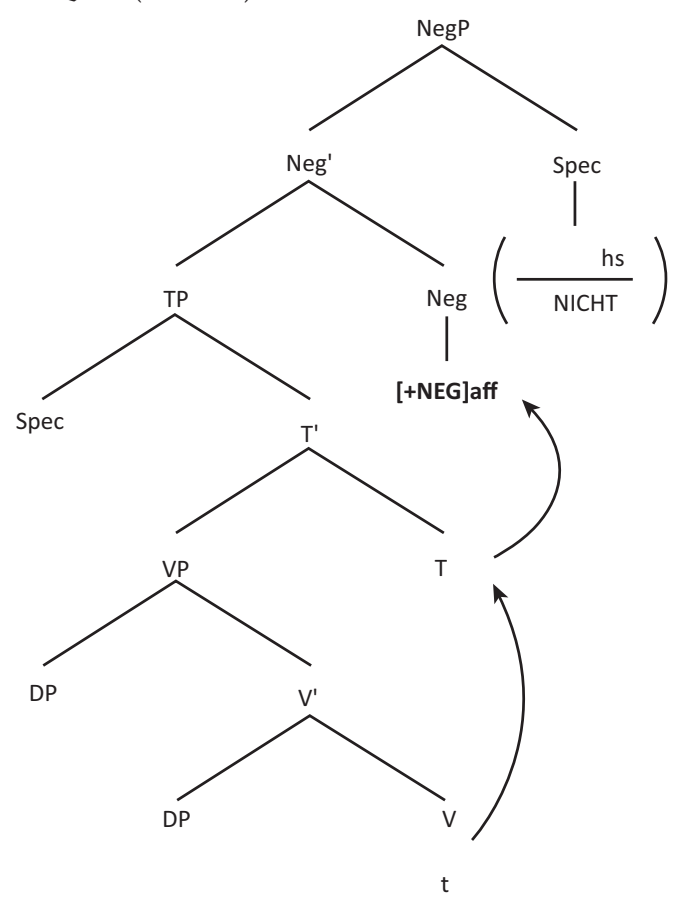

[Eqn 6] 


\section{Current research on SASL}

Syntactic research on SASL appears to be largely an unexplored area of study. Vermeerbergen et al. (2007) provide the most relevant study, in which they compare SASL with Flemish Sign Language in an attempt to try and highlight key differences and similarities between the two unrelated sign languages. Of particular interest is their finding on the word order of SASL. They posit that SASL has, in most cases, an SOV or OSV word order. However, this is currently the only study we are aware of that attempts to describe SASL's basic word order. Other studies have focused on the syntax of classifier predicates in SASL (Aarons \& Morgan 2003).

\section{Collecting and analysing SASL data}

Sign languages present several unique challenges for the researcher as there are a variety of factors that must be accounted for to ensure that the data collected is valid and reliable. These factors are interrelated with each other; language acquisition, deaf education, language attitudes, bilingualism, language accommodation and methods of data collection all impact on each other, and understanding the way in which these complex factors relate is crucial for designing the methodology. It is for this reason that we discuss our methodology in detail here to highlight why specific choices were made in this research.

The main aim of the data collection was to capture a small, naturalistic sample that would reflect some of the uses of negation in SASL. Two rounds of data collection took place. The first was a pilot study that was used to screen out any problems that would interfere with the final data collection. Once the second round of data was collected we selected a set of appropriate tools for each level of analysis so that valid conclusions could be made. For brevity's sake, this section describes only the methods used in the final round of data collection.

\section{Informant selection}

Selecting appropriate informants is paramount to collecting valid data in any research using linguistic field methods. Neidle et al. (2000) provide guidelines for what can be considered as the 'ideal' sign language informant. The 'ideal' informant would have acquired the sign language under investigation in the most natural way, that is, from Deaf ${ }^{5}$ parents who are first language signers. To become a competent native signer or speaker, informants need to have had natural language input from a young age. The first problem this presents for sign language research is that about 95\% of deaf children are born to hearing parents (Mitchell \& Karchmer 2004). Without language input from Deaf parents, the deaf child subsequently does not acquire the language in a natural way.

5.We follow the well-established convention of using 'Deaf' to refer to Deaf people as a distinct cultural and linguistic grouping and 'deaf' to refer to people with the audiological condition of hearing loss.
Schools for the deaf can provide an adequate source of linguistic input that can allow children develop a 'native signer' status. If children attend a school for the deaf from a young age they may be considered as suitable candidates as an informant; however due to the nature of the deaf schooling system, this is not without complications. Previously in schools for the deaf in South Africa, there was a strong oralist culture where signing was not encouraged by educators, or if signing was used, it was done in a manually coded variety of a spoken language, such as Signed Exact English, rather than a natural sign language (Reagan 2008). Thus, it is challenging to find candidates who received an adequate amount of input at school to acquire a native-like competence in SASL. The second major challenge is language interference in the sample. The majority of the Deaf population lives in a hearing world, so many of them can be thought of as bilingual. The result of this is that spoken forms find their way into signing. There are instances where codeswitching between manually coded varieties of the spoken language and natural sign languages can affect the validity of the data. This codeswitching can affect word order as well as the lexicon used. The complications associated with language acquisition mentioned above, and particularly the use of manually coded varieties of spoken languages in school, are one factor that can lead to codeswitching in the sample. Another factor is the Observer's Paradox: informants may alter their response to give the researcher what they think is the answer that they are looking for, or to accommodate to hearing researchers by using manual codes of spoken languages. Informants who lack a view of sign languages as prestigious may be inclined to give answers in manual codes of spoken languages. This brings up an important criterion for selecting informants: language attitudes. However, screening for this particular criterion is challenging.

For all these reasons, it is important for hearing researchers on sign languages to pay careful attention to informant selection, to try to collect as naturalistic a sample of data as possible (preferably without the hearing researchers' presence), and to work with an interpreter as we did in this research (see 'Informants' section). All these measures are necessary to minimise or eliminate the occurrence of manual codes of spoken languages in one's data.

\section{Informants}

In order to ensure that the data sample would be a faithful reflection of SASL syntax only native signers were used in the final round of data collection.

The informants that participated consisted of one man, Signer A, and one woman, Signer B. Signer A is considered to be a native signer even though both his parents as well as his siblings are hearing. We classify him as a native signer based on the fact that he was born deaf and attended a school for the deaf from a young age and thus acquired SASL as his first language. He is in regular contact with the Deaf community through involvement with the Deaf Federation of South Africa (DeafSA), making him suitable for the study. His strong 
involvement in the Deaf community and Deaf activism demonstrates that he has a positive attitude towards SASL because language is a crucial aspect of Deaf identity, as demonstrated in Baker-Shenk and Cokely's (1991:56) model of Deaf culture. Signer B is a hearing child of Deaf adults, but considers SASL as her first language and holds SASL in high regard. She is also in regular contact with the Deaf community as a professional sign language interpreter and trainer of interpreters, making her an ideal informant. Signer B also acted as an interpreter in our study, interpreting instructions to Signer A prior to the recording session described in the 'Data collection' section, as well as interpreting what he signed during the data session that took place during the coding process described in the 'Coding' section. Signers A and B thus assisted us to overcome the challenges associated with good informant selection in sign language research; both are native signers of SASL, albeit with different backgrounds, and both have strongly positive attitudes towards SASL.

The two signers are friends of each other, and both grew up in the Eastern Cape, although they have both been exposed to many different varieties of SASL. Signer A went to a deaf school in the Eastern Cape, before moving on to other schools for the deaf in Gauteng and KwaZulu-Natal. He also had some post-school education in KwaZulu-Natal. Signer B completed her higher education in Gauteng and interprets for Deaf people in most South African provinces on a regular basis. Despite this, it is possible that during the data collection, the signers may have been signing in a particular social or regional dialect, limiting the generalisability of the findings of this study to SASL as a whole. As a result of the small data set, it is best to conceive of this research as a case study which can serve as a basis for further syntactic research on SASL, at least until more is known about syntactic variation in SASL. A further study on the syntax of wh-questions in SASL has arrived at a more generalisable dataset by asking SASL informants from two different geographical regions to crosscheck each other's signing through indirect grammaticality judgements (De Barros 2016)

\section{Data collection}

In our data collection, we aimed at recording naturalistic conversation between two Deaf signing informants so as to collect enough authentic instances of sentential negation to analyse for this project. The recording was set up in a postgraduate room in the Department of English Language and Linguistics at Rhodes University, a relatively informal space, so that participants could feel at ease and not under any pressure to use more formal registers in their signing, which would be more influenced by Signed English. The two informants were seated next to each other at an angle so that they could see each other while remaining in the field of vision of the cameras. A camera was set up to record each informant's signing to ensure that all details, especially those pertaining to non-manual features, could be captured. The informants were asked to talk about their experiences with education. This topic was chosen because education is an important topic of debate in Deaf culture and would be easy for either of the informants to talk about. After the cameras were started, the informants were left alone in the room with none of the researchers present. The conversation was recorded for an hour. The final data set thus comprised two hour-long video recordings, one of Signer A and the other of Signer B. These recordings were then stored electronically for further analysis. In summary, we were able to overcome some of the methodological challenges posed by language interference by collecting data in as naturalistic a fashion as possible, away from the presence of researchers so as to minimise the effects of the observer's paradox.

\section{Data analysis}

The first step of analysis was to code the data, identifying the various instances of negation. The coding system marked all signs of manual negation and signs of negative incorporation. Non-manual features of negation were coded as either headshake or facial expressions.

\section{Coding}

The interpretation of the data took place over two stages. In the first, the videos containing the data were played back to the two informants. They were asked to note when an instance of negation occurred in the conversation, as we wanted to ensure that we considered all the expressions which were understood by the informants to contain negation. Observations about the video time of each instance of negation and the type of negation present were written down on a table by the researcher. A 'Description' column was also added to contain any piece of information that the informants felt to be of value. Although the recorded conversation was over an hour, due to time constraints only $20 \mathrm{~min}$ of the data could be coded in this way. As mentioned in the 'Informants' section, the small extent of this dataset does limit the generalisability of our findings and also allowed for more focused analysis of a limited number of constructions, which suited the purposes of this case study.

The second step was to isolate the tokens of negation noted by the informants in the video. These were subsequently edited into several smaller video clips so that they could be easily analysed. Deciding where to cut the clips was a major challenge as the clause boundaries were not often clear. Intonation breaks were mostly used to decide the boundaries of the recordings; however, irrelevant information was often included in the clips. There were a total of 42 clips containing a clause or clauses in which one or more tokens of negation were found. Each of these clips was then individually glossed and throughout the glossing process any preliminary observations were noted. Three of the clips were discarded after this process as the informants later noted that there were several hand slips in them, and thus these examples would not accurately reflect the language.

Once the sentences were glossed the tokens of negation were split into two groups: signs of manual negation and negative non-manuals. The signs of manual negation were first 
described by their form. The form of each novel instance is identified using Battison's (1974) four parameters of a sign: handshape, location, palm orientation and movement. Lexical non-manual features of these signs are also identified. The general location of the sign within the clause was noted, as well as whether or not it was accompanied by non-manual negation or facial features.

The negative non-manuals were first divided into headshakes and facial features, and a brief description of each was made. The phonological scope of each non-manual feature was carefully noted. The signs and/or other non-manual features that they co-occurred with were recorded, as well as the nonmanual feature's position within the clause. One of the most important tasks was to establish what the status of the identified non-manual features was in SASL. The conditions of their use were carefully evaluated in the data, looking specifically at whether they carry enough semantic weight to negate a clause on their own.

\section{Challenges related to coding}

The two informants were not freely available to the researchers at all times, as they do not live in the same town as the researchers and had limited time to assist with our research, which made the coding process challenging. The process was much more time-consuming than anticipated, and this was mainly the result of overestimating the linguistic intuitions of the two informants. We had assumed that the informants would easily be able to identify all the tokens of negation; however, this was not the case. Tokens of manual negation were picked out easily and were simple to gloss. The informants were even able to identify idiomatic expressions of negation. On the other hand, though, they were less adept in identifying tokens of non-manual negation. There were multiple instances where the informants missed sentences containing tokens of headshake-only negation. It was only once a researcher queried some uncoded tokens that the informants realised that they had missed them. There are several possible reasons why the informants focused on the manual tokens rather than the non-manual. It may be that forms similar to those from spoken language (such as the manual negators) are seen as more correct, or that the informants wanted to code what they thought the researcher was looking for. There may also be a lack of linguistic intuition surrounding non-manuals because they are lessresearched forms than spoken components of negation.

\section{Syntactic analysis}

After having located and identified the various forms of negation found in the data, the Principles and Parameters Model was employed to explain the structure of negation in SASL. First, the position of the negative element in relation to the verb was described as either being preverbal or postverbal. Next, the constituents frequently found under the scope of the headshake negation were noted. The rules governing the distribution of these negative elements were then analysed as either being syntactic or morphological. Using this information similar structures found in the literature on other sign languages were compared with SASL. Once an analysis was found that seemed to be a closest fit to the structure of negation in SASL, we considered whether alterations to this structure were necessary to account for any additional characteristics of SASL.

\section{The form and structure of negation in SASL}

In this section we describe the phonetic forms taken by the various markers of negation in SASL, beginning with manual negators (see 'Manual negation' section) and continuing with non-manual features of negation (see 'Non-manual features of negation' section). Following this, we put forward a brief analysis of the syntactic structure of sentential negation in SASL (see 'Summary of negation in SASL' and 'The syntax of sentential negation in SASL' sections).

\section{Manual negation}

As mentioned in the 'Components of sign language negation' section, manual negators can be classified into negation signs and negative particles on the one hand, which are more productive forms of negation, and signs of negative incorporation, which are less regular, on the other hand. The forms that these take in SASL are described in the 'Negation signs' and 'Signs of negativeincorporation' sections, respectively.

\section{Negation signs}

The negative particle NOT was identified as the manual negation sign most commonly used in sentential negation for SASL. Similarly to the sign languages reported in the literature (see 'Sentential negation' section), the manual negation sign is also optional in SASL. NOT always occurs after the verb and is accompanied by the side-to-side headshake. If another manual negative sign is used in the clause, then the NOT is dropped. The phonetic form taken by this sign is described below. In this and subsequent descriptions of manual signs, we have omitted descriptions of non-manual features, as these are described in detail in the 'Non-manual features of negation' section.

\section{NOT (meaning: 'not'; see Figure 1):}

- This is signed with two hands in the B handshape, fingers pointing forward.

- The location is in front of the signer in the neutral space.

- The palms face each other.

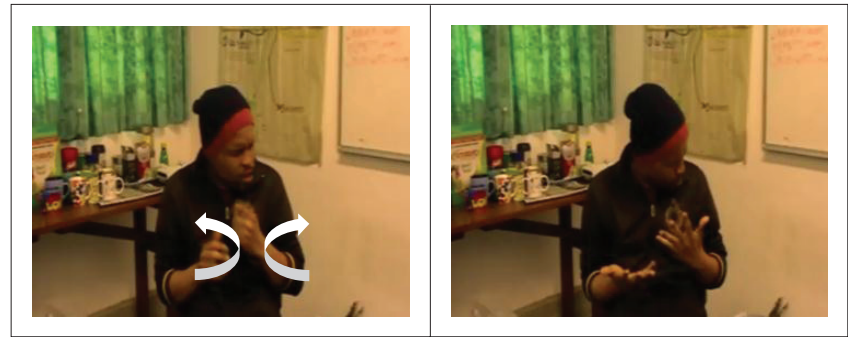

FIGURE 1: NOT (SASL). 
- The hands rotate outwards so that palms end facing upwards.

The other manual negation sign identified is NOTHING and is found frequently in the data. Although it is not obligatory, it is found in several negative clauses in our data. It always occurred in the clause-final position and was always accompanied by the side-to-side headshake. The productive nature of this sign would suggest that it may have an additional function in the negative clause as being a negative existential or negative quantifier; however, more research would be needed to confirm this. The phonetic form of this sign is described below.

NOTHING (meaning: 'nothing or not at all'; see Figure 2):

- This is signed with two hands in the O handshape.

- The location is in front of the signer in the neutral space.

- The palms face each other.

- The movement is a repeated side-to-side movement.

\section{Signs of negative incorporation}

The signs of negative incorporation that were found in our SASL data appear to be consistent with the literature as similar forms are reported in other sign languages. They appeared in the clause-final position and were also always accompanied by the side-to-side headshake.

Zeshan (2004) reports that the negative modal CANNOT is frequently used in sign language. The informants would frequently make use of either NOTHING or CANNOT to accompany the negative clause in the SASL data and suggest that this is an important strategy for negation in SASL. The phonetic form of this sign is described below.

CANNOT (meaning: 'cannot'; see Figure 3):

- This is signed with two hands in the G handshape.

- The location is in neutral space in front of the signer.

- The palms begin facing away from the signer.

- The movement is a downward twisting motion that ends with hands twisting up again to allow the palms to face the signer.

Various other signs of negative incorporation used in SASL are described below.

MATTER-NOT (meaning: 'does not matter'; see Figure 4):

- This sign begins with two hands in the B handshape and ends with a $G$ handshape.

- The location is in front of the signer's chin.

- The sign begins with the palms facing downwards and ends with them facing away from the signer.

- The movement is away from the signer into neutral space.

LIKE-NOT (meaning: 'do not like'):

- This is signed with one hand in the G handshape.

- The location is in front of the signer's mouth on the ipsilateral side.

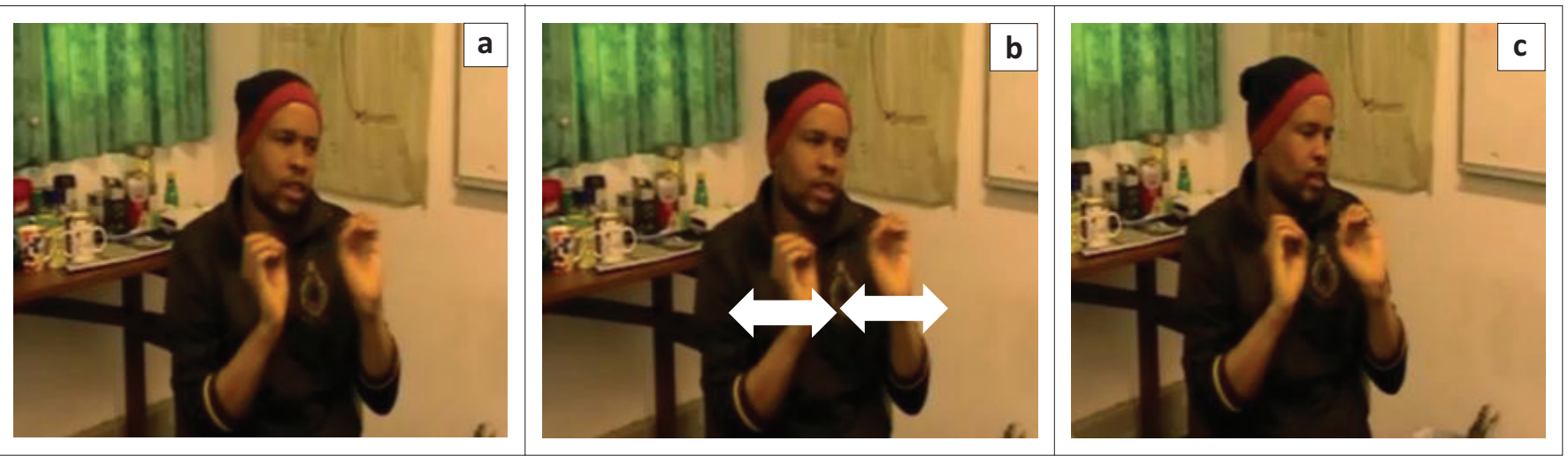

FIGURE 2: NOTHING (SASL).
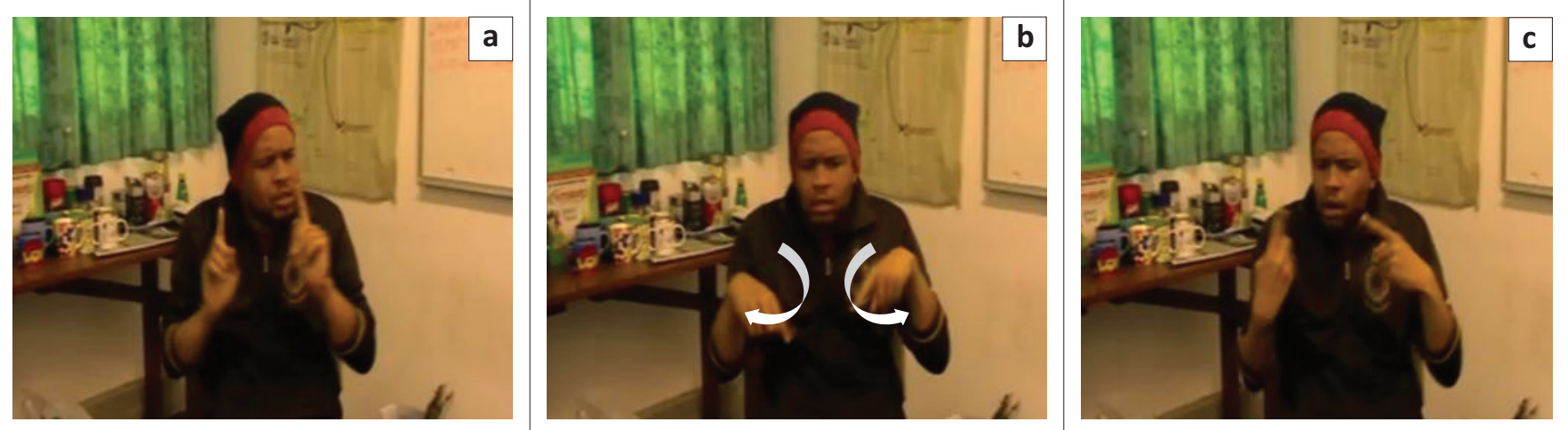

FIGURE 3: CANNOT (SASL). 


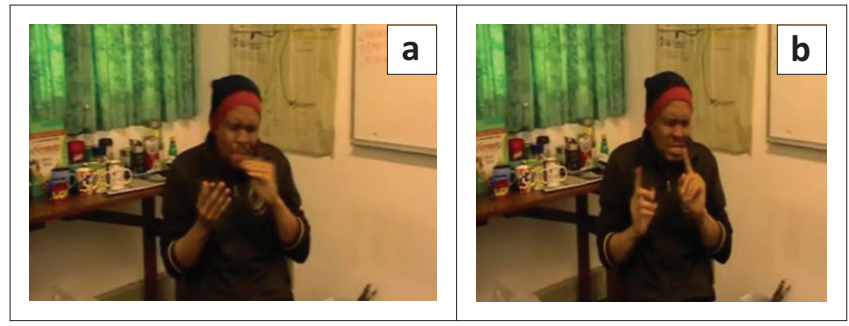

FIGURE 4: MATTER-NOT (SASL).

- The palm faces downwards.

- The movement is away from the signer towards the contralateral side.

KNOW-NOT (meaning: 'do not understand'):

- This is signed with one hand in the D handshape.

- The location is beside the ipsilateral side of the head.

- The index finger touches the upper head and the palm orientation is to the contralateral side.

- The hand moves behind the signer's head.

HEAD-EMPTY (meaning: 'do not know/ignorant'):

- This is signed with one open B hand and ends in a bent B.

- The location is in front of the signer's forehead on the ipsilateral side.

- The palm is facing the signer.

- The movement is across the forehead to the contralateral side and back.

\section{Non-manual features of negation}

As identified in the 'Non-manual negation' section, there are also two types of non-manual features of negation: headmovements (described in the 'Negation head-movements' section) and facial expressions (described in the 'Facial expressions of negation' section).

\section{Negation head-movements}

The side-to-side headshake that is reported so widely in the literature (see 'Negation head-movement' section) is a nonmanual feature of negation that SASL makes extensive use of. Headshake negation has the highest frequency out of all the classes of negation in our data. It could be used in isolation to negate the verb, but also frequently accompanies manual negation signs. The data show that the minimal scope of the side-to-side headshake was always over the matrix verb of the clause, and the maximum scope was over the verb phrase and the manual signs of negation. This obligatory occurrence and fixed scope suggests that in SASL, headshake negation is the chief clause negator.

\section{Facial expressions of negation}

The literature discusses several different forms of facial expressions used to convey negation in various sign languages. For the purposes of this study only one prominent form is considered. This form is described as a 'frown' where the eyebrows are lowered. This is frequently accompanied by pursed lips and a wrinkled nose. What is of importance to this study is the status of this particular facial expression in SASL. Although it appeared frequently and in a number of contexts, it was never found occurring without another form of negation. This facial feature also had a far more varied scope than that of side-to-side headshake, co-occurring with a number of different constituents. There were even several instances where the facial feature's scope spanned over the subject/topic of the sentence, (see Eqn 7).

SASL:

\begin{tabular}{lrr} 
& & headshake \\
\cline { 2 - 3 } & & frown \\
\hline MOTHER SHOCK & SPEAK & NOT \\
My mother was shocked that I could not speak
\end{tabular}

Negation spreading over the topic is highly unusual and suggests that the facial feature does not have a grammatical function. We therefore assume that facial expressions alone in SASL are not sufficient to signal negation. Instead they are considered to be affective expressions that may occur with manual signs and headshakes. Having said this, although they do not function on a morphosyntactic level, the data suggest that this facial feature may be discourse-related.

\section{Summary of negation in SASL}

In SASL, the side-to-side headshake is considered to be the chief clause negator. The data show four types of grammatical structures for negation in SASL. The first is headshake only, which co-occurs with the verb (as seen in Eqn 8a). The second is with the negative particle NOT, where the headshake spans over the verb and the manual negation sign (as shown in Eqn 8b).

The next two constructions show the negative headshake spanning over the manual sign NOTHING (in Eqn 8c) and over the sign of negative incorporation CANNOT (in Eqn $8 \mathrm{~d})$. In all the constructions, the scope of the headshake never spans over the subject or topic of the sentence. The negation always appears to be clause-final and has to spread over the verb.

SASL:

(a) PEOPLE I MEET
I did not want to meet the people

(b) MOTHER SHOCK SPEAK NOT

My mother was shocked that I could not speak

(c) MEET NOTHING

(We) had not met at all

(d) HEAR CANNOT

headshake

(I) cannot hear

[Eqn 8]

The next section is aimed at explaining the first two constructions syntactically. The sentence containing nothing 
and the sign of negative incorporation cannot have been left out as the literature suggests that these pattern differently to the negative particle, not (Antzakas 2006). For this reason, they are beyond the scope of this article; instead a comprehensive analysis of the syntax of negative particle in SASL is given, and this can form a basis for future research.

\section{The syntax of sentential negation in SASL}

There has been a considerable amount of work done on identifying and describing negation in sign languages; however, few people have taken the next step to describe the process of negation formally (Pfau \& Quer 2003). In this section we do this by building on the few syntactic analyses that are available for sign languages and modifying them to describe sentential negation in SASL. Further research will have to be conducted to cross-check the following analysis. The aim of this analysis was to provide a structure that may be subsequently refined and improved upon.

As shown in the 'Placement of sentential negation and word order in sign language' section, the syntactic trees for ASL, DGS and LSC, as drawn by Pfau and Quer (2003), are very different from each other. Looking at the data (see Table 1), negation in ASL appears to be the least similar to SASL, followed by LSC. However, negation in DGS appears to function in a very similar way to negation in SASL. In both sign languages, the negation is postverbal and clause-final, the minimal scope of the headshake is always over the matrix verb and when the negative particle is present, the headshake scopes over both the verb and this manual sign. This provides a substantial amount of evidence to suggest then that the [+neg] feature is morphological in SASL, as it is in DGS and LSC.

In SASL the elements of sentential negation have been identified as the side-to-side headshake and the negative particle NOT. The position of the negation after the verb suggests that SASL could be an OSV or SOV language. This is consistent with the literature where Vermeerbergen et al. (2007) posit that the word order in SASL is usually either OSV or SOV. Most importantly, we see that in SASL the verb is final. For word orders that are verb-final, split-headed structures are often used (see 'Placement of sentential negation and word order in sign language' section). In such languages, functional categories are head-initial and lexical categories are head-final. Thus, we apply a split-headed structure to SASL.
The obligatory nature of the side-to-side headshake suggests that it is the chief clause negator in SASL. The headshake would then carry the [+neg] feature and would be basegenerated in the head of the NegP. The minimal scope of this [+neg] feature is always over the matrix verb in SASL. To explain the scope of negation in SASL we assume that this feature is an affix as in DGS. However, this particular affix is not sequential as it occurs simultaneously with the verb. Thus, we consider it to be a featural affix, which, according to Akinlabi (1996) has the same properties of traditional regular affixes, with the exception that they occur as part of other segments and span the entire base of affixation. This explains the simultaneity of the affix in SASL.

In order to explain the syntactic scope of the [+neg] affix, we posit that V-to-Neg raising occurs in SASL, as in DGS and LSC, according to Pfau and Quer's (2003) analysis. This is because of the Stray Affix Filter (see 'Placement of sentential negation and word order in sign language' section), where bound morphemes must be attached to the verb. Thus, the verb raises to the head of the NegP and is affixed to the [+neg] morpheme, as is illustrated in (Eqn 9).

\section{WE}

'We did not meet'. Adapted from Pfau and Quer (2003:79):

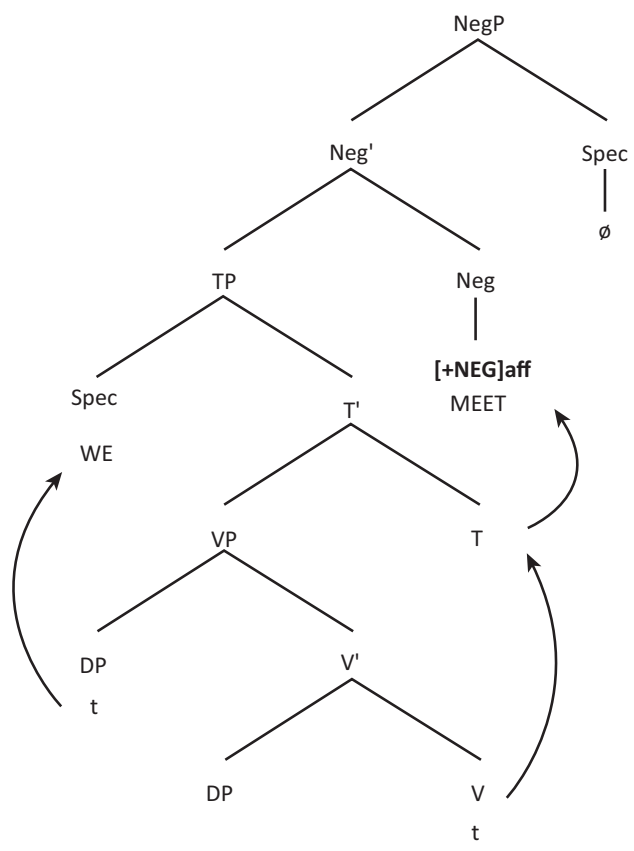

[Eqn 9]

TABLE 1: Comparison of the properties of sentential negation in SASL, ASL, DGS and LSC.

\begin{tabular}{|c|c|c|c|c|}
\hline Variable & SASL & ASL & DGS & LSC \\
\hline Placement of negation & Postverbal & Preverbal & Postverbali & Postverbal $\dagger$ \\
\hline Status of headshake & Obligatory & Almost obligatory $\dagger$ & Obligatory $\dagger$ & Obligatory $\dagger$ \\
\hline $\begin{array}{l}\text { Scope of headshake when there } \\
\text { is no manual negation present }\end{array}$ & Over the matrix verb & $\begin{array}{l}\text { Over the matrix verb and the } \\
\text { object in the DP }\end{array}$ & Over the matrix verb $\dagger$ & Over the matrix verb $\dagger$ \\
\hline $\begin{array}{l}\text { Scope of headshake when there is } \\
\text { manual negation present }\end{array}$ & $\begin{array}{l}\text { Over the matrix verb and the } \\
\text { manual negation sign (NOT) }\end{array}$ & $\begin{array}{l}\text { Over the manual negation } \\
\text { sign (NOT) }\end{array}$ & $\begin{array}{l}\text { Over the matrix verb and the } \\
\text { manual negation sign (NICHT) } \dagger\end{array}$ & $\begin{array}{l}\text { Over the manual negation } \\
\text { sign (NO) }\end{array}$ \\
\hline Properties of [+neg] & ? Morphological & Syntactic & Morphological $\dagger$ & Morphological $\dagger$ \\
\hline
\end{tabular}

$\dagger$, indicates properties similar to those of SASL.

SASL, South African Sign Language; ASL, American Sign Language; DGS, German Sign Language; LSC, Catalan Sign Language.

Source: Adapted from Pfau and Quer (2003) 
This accounts for the headshake over the verb as well as the scope not branching beyond the NegP - that is, it is able to explain why the scope does not spread to the subject in the $\mathrm{TP}$ or a direct object in the VP. The split-headed tree also allows for the negation to be clause-final. This structure is illustrated in (Eqn 9).

The negative particle NOT in SASL functions as depicted in (Eqn 10). V-to-Neg raising is still applied to the structure as the minimal scope of the headshake must still be over the verb. The negative particle is said to be base-generated in Spec-NegP and is lexically specified for a headshake. This accounts for the headshake co-occurring with the manual negator NOT, as well as this manual negator occurring after the verb:

\section{WE MEET NOT}

'We did not meet' (SASL). Adapted from Pfau and Quer (2003:79):

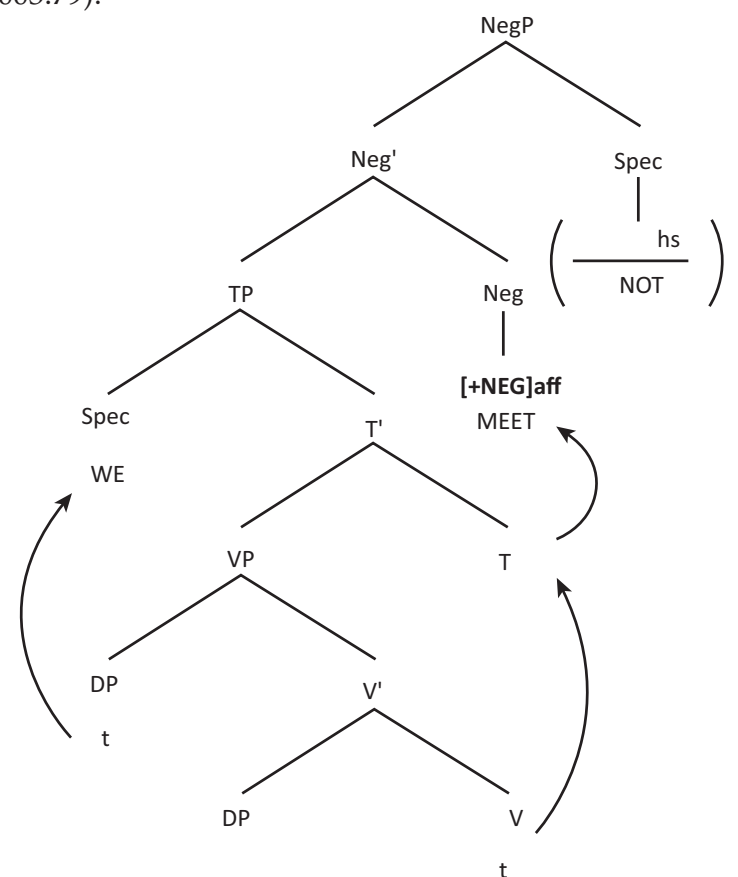

[Eqn 10]

In the above constructions, we see that all the features are checked. WE, which is base-generated in Spec-VP, minimally $\mathrm{m}$-commands ${ }^{6}$ the verb and, thus, is able to receive the theta role of agent from the verb. WE then moves to Spec-TP where it is assigned nominative case.

\section{Conclusion and directions for future research}

The results of this study indicate that SASL employs the same four forms of negation found in other sign languages, namely negation signs, signs of negative incorporation, headmovements and facial features. Two forms were identified as

6.M-command: If $X$ and $Y$ are two nodes in a syntactic tree, $X$ m-commands $Y$ if and only if: $X$ does not dominate $Y, Y$ does not dominate $X$ and the maximal projection of $X$ dominates $Y$ (Chomsky 1986). marking sentential negation: the side-to-side headshake and the negative particle NOT. These two features were found to operate in the same way in SASL as in DGS. The two syntactic structures posited by Pfau and Quer (2003) for sentential negation in DGS were applied to SASL.

These structures show that the headshake is obligatory for negation in SASL and must always co-occur with the matrix verb. If the negative particle NOT is included, it will occur after the verb, and the headshake will continue to include the negative particle in its scope. The simultaneous nature of the headshake is captured in the structure by describing it as a featural affix. If this is true, then the phonological scope of the non-manual feature is co-extensive with its morphological scope, that is, the signs to which it is affixed.

Moreover, the same structures have been applied to various spoken languages: a split-headed analysis (see 'Placement of sentential negation and word order in sign language' section) has been used for Persian which has an SOV word order (Roberts 2000); featural affixes have been reported in several languages such as Japanese (Akinlabi 1996), and the functional category of NegP is used extensively in spoken languages to explain sentential negation (Haegeman 1995). Thus sign languages make use of the same structures found in spoken languages, but these are realised in a different way because of the alternative modality that they employ.

SASL is a largely untapped linguistic resource in South Africa, and further research on this language is desperately needed. This article suggests that a more comprehensive description is needed for various forms of negation found in SASL. Once this study is replicated with the participation of signers using a number of varieties of SASL to check its validity, the next step could include a description of negative concord between the various forms of negation in SASL. This would include a syntactic analysis of elements such as NOTHING and signs of negative incorporation such as CANNOT, which are used to accomplish constituent negation and so are beyond the scope of this analysis. Given the scarcity of descriptions of SASL's formal features, any research on these features is to be welcomed and can contribute to the recognition of SASL as a language able to be used in official domains in South African society, including education.

\section{Acknowledgements}

The authors wish to thank Asanda Katshwa, Mfundo Lebaka and Kirsty Maclons for their assistance with data collection and analysis in this study.

\section{Competing interests}

The authors declare that they have no financial or personal relationships which may have inappropriately influenced them in writing this article. 


\section{Authors' contributions}

C.D. was responsible for the data collection, analysis and initial writing of this article. I.S. conceptualized and planned this research in collaboration with C.D. and made critical revisions to the article.

\section{References}

Aarons, D. \& Akach, P., 1998, 'South African Sign Language - One language or many? A sociolinguistic question', Stellenbosch Papers in Linguistics 31, 1-28. http:// dx.doi.org/10.1353/sls.2003.0001

Aarons, D. \& Morgan, R.Z., 2003, 'Classifier predicates and the creation of multiple perspectives in South African Sign Language', Sign Language Studies 3(2), 125-256.

Akinlabi, A., 1996, 'Featural affixation', Journal of Linguistics 32(2), 239-289. http:// dx.doi.org/10.1017/S0022226700015899

Antzakas, K., 2006, 'Aspects of morphology and syntax of negation in Greek Sign Language', PhD thesis, Department of Language \& Communication Science, City University London.

Baker-Shenk, C.L. \& Cokely, D., 1991, American Sign Language: A teacher's resource text on grammar and culture, Gallaudet University Press, Washington, DC.

Battison, R., 1974, 'Phonological deletion in American Sign Language', Sign Language Studies 5(1), 1-19. http://dx.doi.org/10.1353/sls.1974.0005

Bussman, H., 1996, Routledge dictionary of language and linguistics, transl. G. Trauth \& K. Kazzazi (eds.), Routledge, London.

Chomsky, N., 1982, Some concepts and consequences of the theory of government and binding, MIT Press, Cambridge, MA.

Chomsky, N., 1986, Barriers, MIT Press, Cambridge, MA.

Cinque, G., 1999, Adverbs and functional heads, Oxford University Press, Oxford.

De Barros, C., 2016, 'Wh-question formation in South African Sign Language', MA thesis, Department of English Language and Linguistics, Rhodes University.

Haegeman, L., 1995, The syntax of negation, Cambridge University Press, Cambridge. http://dx.doi.org/10.1017/CBO9780511519727

Klima, E., 1964, 'Negation in English', in J.A. Fodor \& J.J. Katz (eds.), The structure of language: Readings in the philosophy of language, pp. 246-323, Prentice-Hall, Englewood Cliffs, NJ.

Lasnik, H., 1981, 'Restricting the theory of transformations: A case study', in N. Hornstein \& D. Lightfoot (eds.), Explanation in linguistics: The logical problem of language acquisition, pp. 125-145, Longman, London.
Lasnik, H., 1995, 'Verbal morphology: Syntactic structure meets the Minimalist Program', in $\mathrm{H}$. Campos \& P. Kempchinsky (eds.), Evolution and revolution in linguistic theory: Essays in honor of Carlos Otero, pp. 251-275, Georgetown linguistic theory: Essays in hono
University Press, Washington, DC.

Liddell, S., 2003. Grammar, gesture and meaning in American Sign Language, Cambridge University Press, Cambridge.

Mitchell, R.E. \& Karchmer, M.A., 2004, 'Chasing the mythical ten percent: Parental hearing status of deaf and hard of hearing students in the United States', Sign Language Studies 4(2), 138-163. http://dx.doi.org/10.1353/sls.2004.0005

Neidle, C., Kegl, J., MacLaughlin, D., Bahan, B. \& Lee, R., 2000, The syntax of American Sign Language: Functional categories and hierarchical structure, MIT Press, Cambridge, MA.

Penn, C. \& Reagan, T., 1990, "How do you sign "apartheid?" The politics of South African Sign Language', Language Problems \& Language Planning 14(2), 91-103. http://dx.doi.org/10.1075/Iplp.14.2.02pen

Perniss, P., Pfau, R. \& Steinbach, M., 2007, 'Can't you see the difference? Sources of variation in sign language', in P. Perniss, R. Pfau \& M. Steinbach (eds.), Visible variation: Cross-linguistic studies in sign language structure, pp. 1-34, Mouton, Berlin.

Pfau, R. \& Quer, J., 2003, 'V-to-Neg raising and negative concord in three sign languages', Rivista di Grammatica Generativa 27, 73-86.

Pollock, J.-Y., 1989, 'Verb movement, Universal Grammar and the structure of the IP', Linguistic Inquiry 20(3), 365-424.

Reagan, T., 2008, 'South African Sign Language and language-in-education policy in South Africa', Stellenbosch Papers in Linguistics 38, 165-190.

Reagan, T., Penn, C. \& Ogilvy, D., 2006, 'From policy to practice: Sign language development in post-apartheid South Africa', Language Policy 5, 187-208. http:// dx.doi.org/10.1007/s10993-006-9002-y

Roberts, T., 2000, 'Clitics and Agreement', PhD thesis, Department of Linguistics and Philosophy, Massachusetts Institute of Technology.

Sandler, W. \& Lillo-Martin, D., 2006, Sign Language and linguistic universals, Cambridge University Press, Cambridge.

Sutton-Spence, R. \& Woll, B., 1999. The linguistics of British Sign Language: An introduction, Cambridge University Press, Cambridge.

Woodward, J.C., 1974, 'Implication variation in American Sign Language: Negative incorporation', Sign Language Studies 5, 20-30. http://dx.doi.org/10.1353/ sls.1974.0006

Vermeerbergen, M., Van Herreweghe, M., Akach, P. \& Matabane, E., 2007, 'Constituent order in Flemish Sign Language (VGT) and South African Sign Language (SASL): A cross-linguistic study', Sign Language \& Linguistics 10(1), 23-55. http://dx.doi. org/10.1075/sll.10.1.04ver

Zanuttini, R., 1997, Negation and clausal structure, Oxford University Press, Oxford.

Zeshan, U., 2004, 'Hand, head and face: Negative constructions in sign languages', Linguistic Typology 8(1), 1-58. http://dx.doi.org/10.1515/lity.2004.003 